\title{
EMSOS Congress and Symposium of the Nurse Group Program
}

Wednesday, 22 May 2002

14:30-17:00 Registration of EMSOS and Nurse Group participants at the Faculty Club, Rapenburg 6 (Leiden city centre).

16:30-17:45 Joint welcome reception by the Mayor of Leiden and the Board of Leiden University at the Town Hall.

Thursday, 23 May 2002

08:00 Registration desk open and mounting of posters

EMSOS Congress Lecture Hall 1

08:30-08:40 President's opening remarks

\section{A. Diagnosis and treatment of borderline lesions}

08:40-09:05 R. Fodde: Molecular background of desmoid tumours

09:05-10:15 Free Presentations

1 Desmoid tumors. A Clinical Review of 30 Patients with more than 20 years follow-up-Dalén BPM, Goteborg, Sweden

2 Diagnostic impact of histologic parameters in differentiating enchondroma from grade I central Chondrosarcoma-Hogendoorn PCW, Leiden, The Netherlands

3 BCL-2 Immunohistochemistry as a tool to distinguish osteochondroma and grade I peripheral Chondrosarcoma-Bovee JVGM, Leiden, The Netherlands

4 The treatment of benign and low-grade malignant intramedullary chondroid tumors with curettage and Cryosurgery-Schreuder HWB, Nijmegen, The Netherlands 5 The atypical Lipoma-Sommerville SMM, Birmingham, UK

10:15-10:45 Plenary selected poster review on borderline lesions: R. Veth

10:45-11:15 Coffee break and poster viewing

11:15-12:00 EMSOS lecture

J.C. Clevers: Fundamental mechanisms of tumourigenesis

12:00-12:15 Discussion

12:15-13:30 Lunch

\section{B. Hereditary background in bone and soft-tissue tumours}

13:30-13:55 M. Breuning: Overview of hereditary aspects of bone and soft-tissue tumours

13:55-15:15 Free presentations

22 Osteosarcoma subtypes in Osteosarcoma patients with multiple primary malignancies. Can rare subtypes be indicative for cancer syndromes related with Osteosarcoma?-Hauben EI, Eindhoven, The Netherlands

23 Gene and protein expression profiling in fibroblasts carrying a LI-Fraumeni p53 Germline mutation that induces Chemoresistence to Doxorubicin-Sangiorgi L, Bologna, Italy

24 Somatic and Germical alteration of the TP53 Gene in pediatric Osteosarcoma-Pati o A, Pamplona, Spain

25 Chromosome 9 alterations and p16 expression in Central Chondrosarcomas-Rozeman L, Leiden, The Netherlands

26 Identification and clinical validation of candidate target Genes from the amplified Region on Chromosome Arm 17Q in malignant peripheral nerve sheath tumours-Smeland S, Oslo, Norway 27 Association between the occurance of Breast Cancer and cartilaginous tumors: Phenotopic characterization of a Hitherto unrecognized potential hereditary trait-Cleton-Jansen AM, Leiden, The Netherlands

15:15-15:45 Tea break and poster viewing

15:45-16:15 Plenary selected poster review on hereditary tumours: Stefan S. Bielack 


\section{Surgery and soft tissue tumours}

16.15-17.15 Free presentations

79 Reliability of risk factors and scoring systems in predicting fracturing in metastatic femoral bone lesions-Linden YM van der, Leiden, The Netherlands

80 Predictors of wound complications following free and pedicled soft tissue flaps for reconstruction after excision of soft tissue tumours-Abudu A, Birmingham, UK

81 Silver-coated tumor endoprostheses for prevention of deep infection-Gosheger G, Münster, Germany

82 Our experience with the capanna method of Limb reconstruction using free fibular grafts and cadaveric allograft report of 16 consecutive patients-Bickels J, Tel Aviv, Israel

17:15-17:45 Plenary selected poster review on Surgery and soft tissue tumours

\section{Symposium of the EMSOS Nurse Group Lecture Hall 2}

08:45-09:00 Opening: Cristiana Forni

\section{G. Long-term side-effects after treatment in young adult survivors of childhood cancer}

09:00-09:40 Guest speaker: N.E. Langeveld

127 Quality of life in young adults who are long-term survivors of childhood Bone Cancer

09:40-09:50 Discussion

Moderators: M.A.M. Kroeze, J. Ouwerkerk

09:50-10:10 128 The hidden Long-term effects of treatment-Riley V, London,UK

10:10-10.30 129 Functional outcome following Endo-prosthetic replacement (EPR) for Bone Tumours involving the Knee-Williams C, Birmingham, UK

\section{0:30-11:00 Coffee break and poster viewing}

\section{H. Nursing care for patients treated with chemotherapy for bone tumours}

11:00-11:20 130 A structured and effective way to inform Sarcoma Patients-Leyerzapf NAC, Leiden, The Netherlands

11:20-11:40 131 Nursing care for patients treated with Chemotherapy for Bone Tumours the "Euro-Ewing 99" Protocol-Ouwerkerk ED, Leiden, The Netherlands

11:40-12:00 132 How to inform the New Sarcoma Patient?-Forni C, Bologna, Italy

12:00-12.20 133 Wound healing deficiencies after Major Tumour Operations-Lübben K, Münster, Germany

12:20-12:30 Discussion

12:30-14:00 Lunch

\section{Psychosocial aspects for patients and family members}

14:00-14:20 134 The role of Lymphedema treatment in the rehabilitation after Limb-sparing Surgery—Meller I, Tel Aviv, Israel

14.20-14.40 135 The quality of interaction between the operators, the Oncological patient and his family-Tanganelli F, Florence, Italy

14.40-15.00 136 Project for a school service-Forni C, Bologna, Italy

15.00-15.20 137 The experience of having Cancer-Woodford J, Middlesex, UK

15:20-15:45 Tea break and poster viewing

15:45-16:30 Guest speaker: N. Donders

$\begin{array}{ll}16.30 & \text { Closing remarks }\end{array}$

Friday, 24 May, 2002

\section{EMSOS Congress}

$\begin{array}{ll}\text { 08:00-08:45 } & \text { General assembly } \\ \text { 08:45-09:00 } & \text { Coffee break }\end{array}$

D. Imaging of primary and recurrent tumours

09:00-09:25 J.L. Bloem: Imaging modalities of bone and soft-tissue tumours 
09:25-10:30 Free communications

41 The role of functional nuclear scanning in the management of cartilaginous tumours-Choong P, Melbourne, Australia

42 3-D imaging in planning and monitoring biological reconstructions in orthopaedic oncology: A computer assisted approach. Future perspectives and preliminary results-Manfrini M, Bologna, Italy

43 Value of dynamic contrast-enhanced MR imaging in diagnosing and classifying peripheral vascular malformations-Rijswijk CSP van, Leiden, The Netherlands

44 Hip and Sacroileac joint infitration in sarcoma around the pelvis based on imaging and pathoanatomical correlation studies and its implications on surgical strategy-Lindner NJ, Münster, Germany

10:30-11:00 Coffee break and poster viewing

11:00-11:30 Plenary selected poster review on imaging: D. Vanel

11:30-11:50 Report of the Nurses' Symposium

\section{E. Chemotherapy and other}

11:50-12:35 Free presentations

98 Comparison of Doxorubicine versus VP16-ifosfamide in addition of high dose methotrexate as pre-operative Chemotherapy in Osteosarcomas. A randomized trial by the French Society of Pediatric Oncology—Brugières LB, Villejuif, France

99 Gene therapy of Osteosarcoma: Targeting Adenoviruses towards integrins increases transduction efficiency and tumor cell kill in vitro and in vivo-Witlox MA, Amsterdam, The Netherlands 100 Ewing tumor (ET) of the Spine - experience of the cooperative Ewing's sarcoma studies (EI)CESS 81-92-Ahrens S, Münster, Germany

$12: 35-13: 45$

Lunch

13:45-14:15 Plenary selected poster review on Chemo and other: P. Picci

14:15-15:00 Campanacci lecture

O. Steen Nielsen: Progress in the treatment of bone and soft-tissue tumours of the extremities

15:00-15:15 Discussion

15:15-15:45 Tea break and poster viewing

\section{F. Upper extremity reconstructions}

15.45-16.45 Free presentations

54 Resection in Primary-malignant scapula tumors-Taminiau AHM, Leiden, The Netherlands 55 Upper Limb reconstruction in Bone Sarcomas of childhood-Manfrini M, Bologna, Italy

56 Upper extremity reconstruction: Is Limb-salvage for Osteosarcoma of the proximal humerus a "Safe" procedure?-Bielack S, Münster, Germany

57 Cemented modular prosthesis in the proximal humerus: long term follow-up-Donati $M$, Bologna, Italy

16:45-17:15 Plenary selected poster review on upper extremity reconstructions: R. Grimer

17.15-17.45 Discussion

17.45-17.55 Closing remarks 


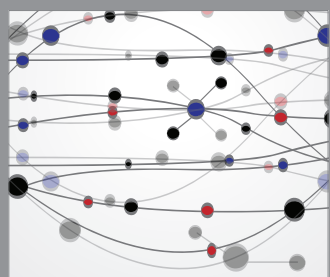

The Scientific World Journal
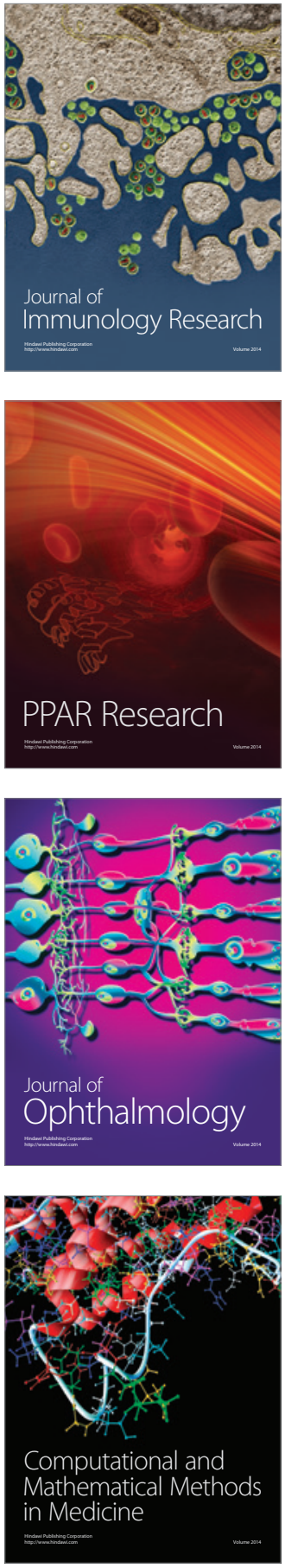

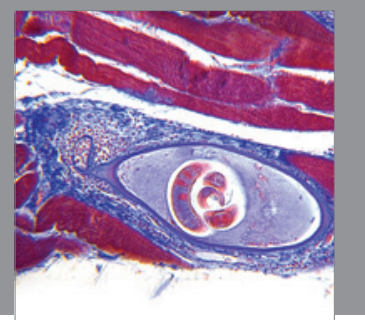

Gastroenterology

Research and Practice
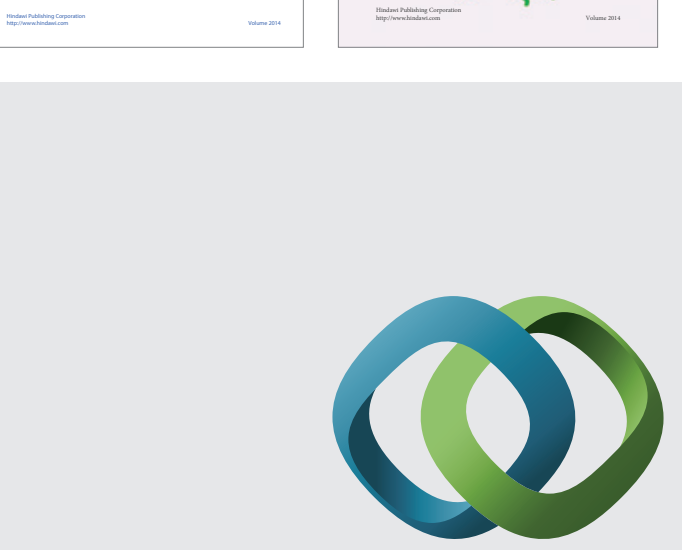

\section{Hindawi}

Submit your manuscripts at

http://www.hindawi.com
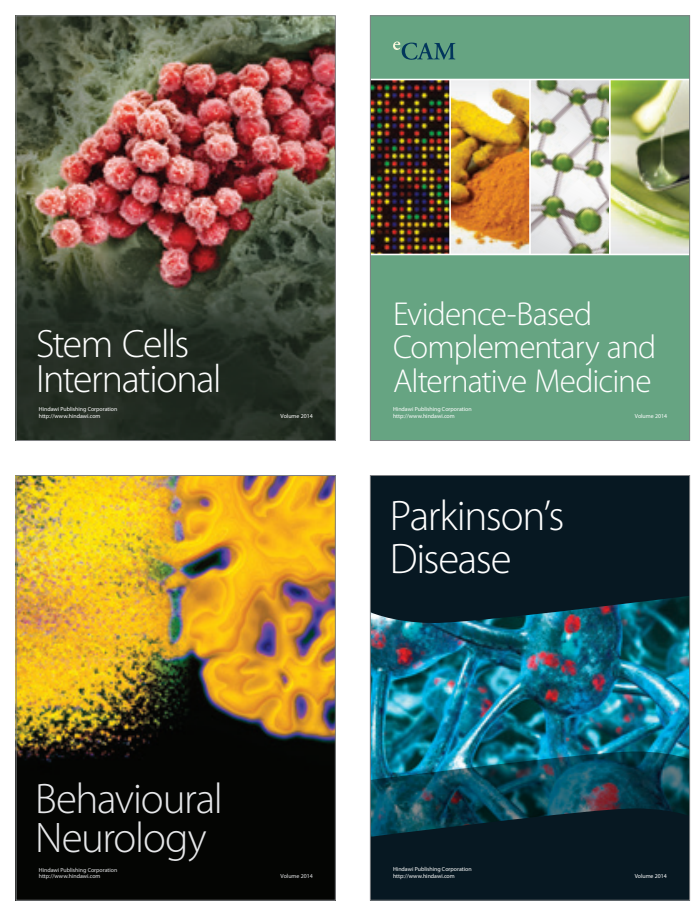

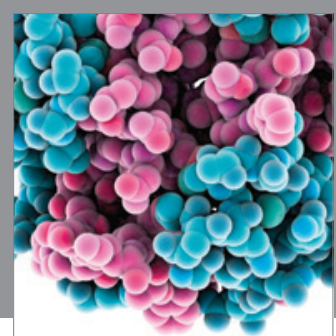

Journal of
Diabetes Research

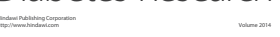

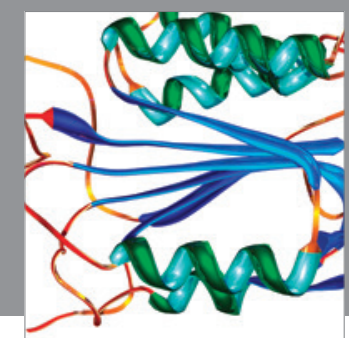

Disease Markers
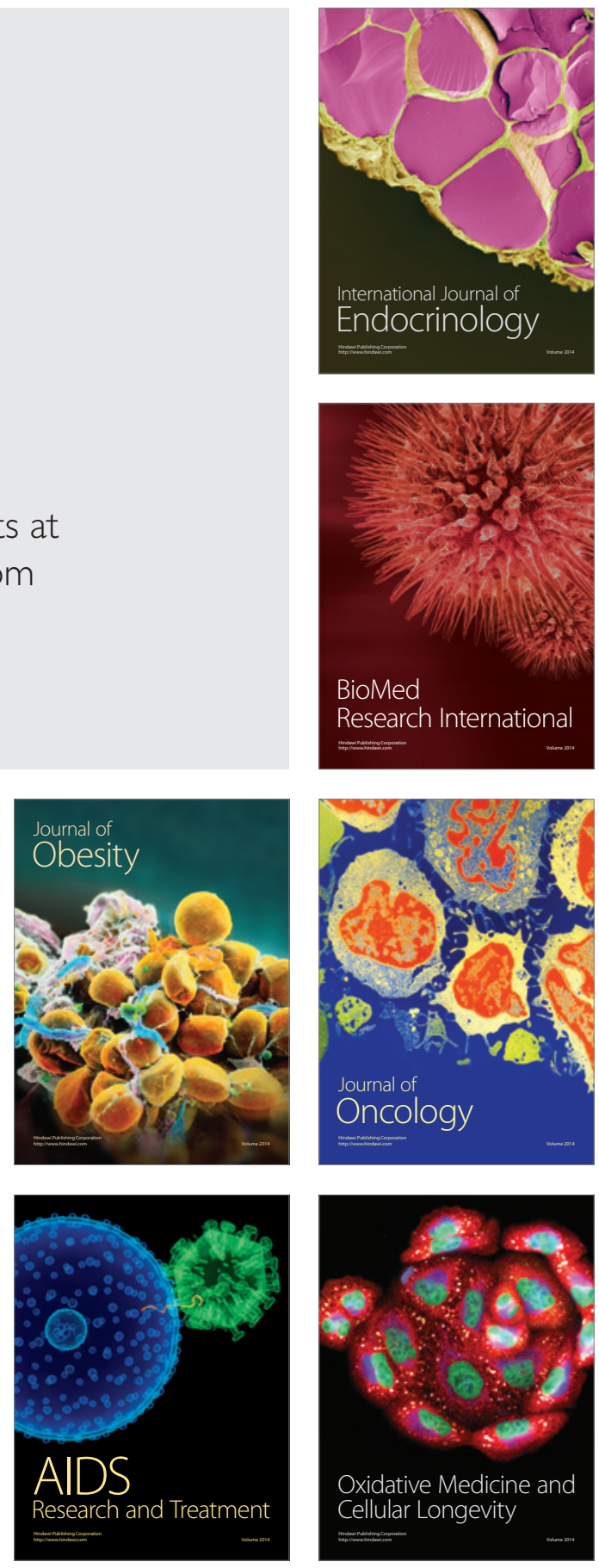